\title{
Participation of the HIM1 gene of yeast Saccharomyces cerevisiae in the error-free branch of post-replicative repair and role Poln in him 1-dependent mutagenesis
}

\author{
E. A. Alekseeva ${ }^{1,2}$ (D) . T. A. Evstyukhina ${ }^{1,2} \cdot$ V. T. Peshekhonov ${ }^{1,2} \cdot$ V. G. Korolev ${ }^{1,2}$
}

Received: 3 August 2020 / Revised: 29 September 2020 / Accepted: 1 October 2020 / Published online: 31 October 2020

(c) The Author(s) 2020

\begin{abstract}
In eukaryotes, DNA damage tolerance (DDT) is determined by two repair pathways, homologous repair recombination (HRR) and a pathway controlled by the RAD6-epistatic group of genes. Monoubiquitylation of PCNA mediates an errorprone pathway, whereas polyubiquitylation stimulates an error-free pathway. The error-free pathway involves components of recombination repair; however, the factors that act in this pathway remain largely unknown. Here, we report that the HIMI gene participates in error-free DDT. Notably, inactivation RAD30 gene encoding Pol $\eta$ completely suppresses himl-dependent UV mutagenesis. Furthermore, data obtained show a significant role of Pol $\eta$ in him 1-dependent mutagenesis, especially at non-bipyrimidine sites (NBP sites). We demonstrate that himl mutation significantly reduces the efficiency of the induction expression of $R N R$ genes after UV irradiation. Besides, this paper presents evidence that significant increase in the dNTP levels suppress him 1-dependent mutagenesis. Our findings show that Pol $\eta$ responsible for himl-dependent mutagenesis.
\end{abstract}

Keywords $H I M 1$ gene $\cdot$ Yeast $\cdot$ Mutagenesis $\cdot$ DNA damage $\cdot$ Post-replication repair

\section{Introduction}

Growing cells need to replicate their DNA with high fidelity to avoid genome instability. During DNA replication, replication fork sometimes encounters a lesion in the DNA template, leading to polymerase stalling. To prevent a replication arrest, cells employ DNA damage bypass mechanisms that allow the complete replication of the genome in the presence of lesions (Friedberg 2005). These DNA damage tolerance processes contribute to survival after DNA damage and sometimes also actively promote the generation of

E. A. Alekseeva

alekseeva_ea@pnpi.nrcki.ru

1 Division of Molecular and Radiation Biophysics, Laboratory of Eukaryote Genetics, Petersburg Nuclear Physics Institute named by B.P. Konstantinov of National Research Centre, Kurchatov Institute, mkr. Orlova Roscha 1, 188300 Gatchina, Russia

2 Division of Molecular and Radiation Biophysics, Laboratory of Eukaryote Genetics, 1)Petersburg Nuclear Physics Institute named by B.P. Konstantinov of National Research Centre «Kurchatov Institute», 2) Kurchatov Genome Center - PNPI, mkr. Orlova Roscha 1, Leningrad District, 188300 Gatchina, Russia mutations. DNA-damage tolerance was termed post-replication repair (PRR) due to the observation that the treatment of budding yeast cells with UV irradiation caused single-strand DNA gaps (Prakash 1981). The UV-induced pyrimidine dimers in the DNA were often retained following "repair", indicating that PRR simply bypasses the damage (Ganesan 1974). Two distinct modes of DDT, error-prone and error-free DDT, operate in all eukaryotic organisms (Sale 2012). Error-prone DDT is mediated by translesion synthesis (TLS), and in error-free pathway, one newly synthesized strand serves as a replication template for the other blocked nascent strand (Branzei et al. 2008; Giannattasio et al. 2014). Cells defective in error-free DDT are characterized by dependency on TLS, showing higher levels of spontaneous mutagenesis and increased damage sensitivity following the inactivation of error-prone DDT components (Cejka et al. 2001). Mutations in the error-free pathway confer a greater sensitivity to DNA-damaging agents than mutations in the TLS pathway (Brusky et al. 2000).

In eukaryotes, two types of damage bypass are controlled by differential ubiquitylation of the proliferating cell nuclear antigen (PCNA), via components of the RAD6 pathway (Ulrich 2009). PCNA is monoubiquitylated on a lysine residue, K164, by the pair Rad6-Rad18, which promotes the 
recruitment of DDT components capable of replicating damaged DNA in a TLS. Extension of this modification with a polyubiquitin chain by the Ubc13-Mms2 and the Rad5 promotes an error-free pathway called template switching (TS).

In recent years, a number of additional factors involved in the TS were reported. In addition to the enzymes promoting PCNA polyubiquitylation, these include the 9-1-1 checkpoint clamp and the Exo1 exonuclease, which contributes to Rad53-dependent activation by widening replication gaps, proteins mediating the strand invasion step $(\operatorname{Rad} 52$ and Shu complex), as well as the helicase Sgs1, implicated in the resolution of TS intermediates (Karras et al. 2013; Vanoli et al. 2010; Ball et al. 2009).

To reveal genes, which control the process of induced mutagenesis, we have developed a method of isolation of the yeast mutants affecting the pathway by the phenotype of enhanced induced mutagenesis. Six mutants have been isolated and designated him (high induced mutagenesis). The himls mutation was induced by nitrosomethylurea and isolated by its feature to increase the frequencies of the nitrous acid-induced ade2-42 reversions (Ivanov et al. 1987a, b). The himl $1 \Delta$ mutant displayed enhanced rates of reversion of the ade2-42 allele, and forward mutations in the ADEl and $A D E 2$ genes induced by nitrous acid (NA) and UV light. The analysis of the genetic interaction of himl $1 \Delta$ mutation with mutations blocking three different repair pathways revealed that the gene, HIM1, participates in post-replication repair (the $R A D 6$ pathway) and recombinational repair (the $R A D 52$ pathway) (Kelberg et al. 2005). In this work, we have shown by genetic methods that the HIMI gene takes part in the error-free branch of post-replicative repair and himls mutant recruitment of Pol $\eta$ in reparative DNA synthesis.

\section{Materials and methods}

\section{Materials}

A PCR-generated natMX6 module and a PCR module containing the URA4 gene from Schizosaccharomyces pombe were amplified from pFLA6A-natMX6 and pFLA6a-URA4 plasmids (Latypov) using SML1_DelL: 5'-TGTCTTATC TGCTCCTTTGTGATCTTACGGTCTCACTAACCTCTC TTCAACTGCTCAATAATTTCCCGCTGCTTCGTACGC TGCAGGTCG-3'; SML1_DelR: 5'-CGAGAATGACAA CAATAGTAGGACGAGAGTCCCTGAAAAGAAGGG TATCTAAGAGAAGAAAAGAACAGAAGCATAGGC CACTAGTGGATC; RAD30 DelL: 5'-ACTTGGAAGGAG TTGATTCAGCTTGGTTCCCCCAGTAAAGCATACGAG TCCTCCTTAGCATGTATCGCCCGCTTCGTACGCTGC AGGTCG-3'; RAD30 DelR: 5'-CTTGTAAAAAATGAT AAGATGTTTTTGGAAGATGTAACTTGTTTCTTCTGA GGTGTGGCAGTATGTTGTGGCATAGGCCACTAGTGG ATC-3'; MMS2_del_L: 5'-TCGATGTCGTGGTGAAAT TCTTATTCTGTATATGCAACGTAGAAGAAAGCAGCG TTTACACAAAAATGTCGCTTCGTACGCTGCAGGTCG -3'; MMS2 del_R: 5'-TTGGAATGCTGCAAATACTGTTTA GGAAAAAGTAGATAACTAAAAGGTTTCTCCTTCCTT CGGTTGACGCGCATAGGCCACTAGTGGATC-3' and XRS2 del_L: ATATAAATGACAGCTTTTTATACATAT AGACCCTTTGAAGAATATTCCAAACTAGAAAGGTTG ATCAGAAGCTTCGTACGCTGCAGGTCG; XRS2 del_R: 5'-TGGTTCTTTTATGTATTAGGCTACTATTTATTTAAT AACTTCGCATCTATCAAAAGAAAAGACTGACTG TGCATAGGCCACTAGTGGATC deoxyoligonucleotides, respectively.
Table 1 Yeast strains used in the work

\begin{tabular}{|c|c|}
\hline Strain & Genotype \\
\hline $11 \mathrm{D}-3031$ & MAT $\alpha$ ade $2 \Delta-248$ ura3-160,188 leu2-3,112 trp1 \\
\hline 1-EAA-3031 & MAT $\alpha$ ade $2 \Delta-248$ ura3-160,188 leu2-3,112 trp1 him1::URA4 \\
\hline 6- DVF-3031 & MAT $\alpha$ ade $2 \Delta-248$ ura3-160,188 leu2-3,112 trp1 sml1::kanMX \\
\hline 7- DVF-3031 & MAT $\alpha$ ade $2 \Delta-248$ ura3-160,188 leu2-3,112 trp1 sml1::kanMXhim1:: URA4 \\
\hline 4-EAA-3031 & MAT $\alpha$ ade $2 \Delta-248$ ura3-160,188 leu2-3,112 trp1rad30::kanMX \\
\hline 5-EAA-3031 & $\begin{array}{l}\text { MAT } \alpha \text { ade } 2 \Delta-248 \text { ura3-160,188 leu2-3,112 trp1 rad30::kanMX } \\
\text { him1:: URA4 }\end{array}$ \\
\hline 6-EAA-3031 & MAT $\alpha$ ade $2 \Delta-248$ ura3-160,188 leu2-3,112 trp1mms $2::$ kanMX \\
\hline 7-EAA-3031 & MAT $\alpha$ ade $2 \Delta-248$ ura3-160,188 leu2-3,112 trp1mms $2::$ kanMX him $1: \because U R A 4$ \\
\hline 2-ETA-3031 & MAT $\alpha$ ade $2 \Delta-248$ ura3-160,188 leu2-3,112 trp1 xrs $2:: U R A 3$ \\
\hline 8-EAA-3031 & $\begin{array}{l}\text { MAT } \alpha \text { ade } 2 \Delta-248 \text { ura3-160,188 leu2-3,112 trp1 xrs } 2: \because U R A 3 \\
\text { him1:: URA4 }\end{array}$ \\
\hline
\end{tabular}




\section{Yeast strains and media}

For culture growth and survival registration, the full medium was used (Zakharov et al. 1984). Alcohol containing medium was used in studies of the UV-induction of mutagenesis (Koval'tsova and Korolev 1996). S. cerevisiae strains used in this work are described in Table 1. The $x r s 2 \Delta$ (2ETA3031) mutant were obtained from the previously described 11D-3031 (MAT $\alpha$ ade24-248 leu2-3,112 ura3-160,188 trp1) strain by gene replacement (Fedorova et al. 2004; Chernenkov et al. 2012a, b). The 11D-3031 strain was transformed with modules, and the transformants were selected on plates with YEPD containing $30 \mathrm{mg} / \mathrm{l}$ nourseothricin and on plates with selective media without uracil, respectively. The single mutants $\operatorname{him} 1 \Delta(1-\mathrm{EAA}-3031), \operatorname{himl}(1-$ EAA-3031), smlla(6-DVF-3031), rad30 $\Delta$ (4-EAA-3031), and $m m s 2 \Delta(6-\mathrm{EAA}-3031)$ and $x r s 2 \Delta(2-\mathrm{ETA}-3031)$ were constructed from previously described 11D-3031, already

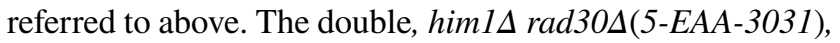

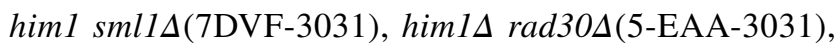
himl $1 \Delta m m s 2$ (7-EAA-3031) and himls xrs24(8-EAA-3031) mutants were also constructed from previously described 11D-3031. All mutants were PCR-verified.

\section{Sensitivity against UV irradiation}

Cell sensitivity against UV irradiation tests were performed on plates by growing an overnight culture of the respective strain in liquid YPD at $30{ }^{\circ} \mathrm{C}$. Cells were washed and resuspended in water at a density of $1 \times 10^{7}$ cell $/ \mathrm{ml}$. Cells were irradiated with a UV lamp BUV-30 (UV-C range). Aliquots were withdrawn at different times, diluted, and plated onto YPD plates to determine the number of survivors.

\section{UV mutagenesis assays}

UV-induced mutagenesis was measured by registering mutations at five ADE loci (Roman 1956). Mutation tests were performed on plates by growing an overnight culture of the respective strain in liquid YPD at $30^{\circ} \mathrm{C}$. Cells were washed and resuspended in water at a density of $1 \times 10^{7}$ cell $/ \mathrm{ml}$. Cells were irradiated with a UV lamp BUF-30. Aliquots were withdrawn at different times, diluted, and plated onto YPD plates to determine the number of survivors. To determine mutation frequency, aliquots without dilution were plated onto a medium YPD containing ethanol instead of glucose, the composition of which has been described earlier (Koval'tsova and Korolev 1996).

In total, five replicates of the experiment were performed; the mean values with $95 \%$ confidence intervals are given on the graphs and in the tables.

\section{can $^{R}$ mutation spectra}

Yeast cell suspensions were irradiated with UV light at $84 \mathrm{~J} /$ $\mathrm{m}^{2}$. Then, cells were harvested by centrifugation and plated on selective medium with canavanine. Independent canavanine-resistant clones were transferred to fresh medium with canavanine. Genomic DNA was isolated from purified $\operatorname{can}^{R}$ colonies using a glass bead lysis procedure. A portion of $c a n^{R}$ locus containing 800 bp was amplified and DNA sequence analysis of PCR-amplified genomic fragments was performed by "Beagle", using the primers 5'-cacaacctctttcacgacg-3 and 5'-ggaaacccaacctaagaacc-3'.

\section{Real-time PCR}

For conducting real-time PCR was used on a CFX96 RTPCR Detection system (Bio-Rad, UK). The reactions were carried out in $25 \mu \mathrm{l}$ volumes consisting of $10 \mu \mathrm{l} 2.5$-fold reaction mixture for RT-PCR in the presence SYBR Green I dye and Rox reference dye (Syntol, Russia), $14.1 \mu \mathrm{l}$ water, $0.7 \mu \mathrm{l}$ of cDNA and $0.1(2 \mathrm{mM})$ respective primers (primers for gene RNR3: ForNR3 5'-ACACCTTTCATGGTTTAT AAG-3' and RevRNR3 5'-CGACGATTTCACAACATA A-3'; for gene ACT1: ForACT1 5'-GAAGGTCAAGATCAT TGC-3' and RevACT1 5'- GTTGGAAGGTAGTCAAAG-3').

PCR cycling conditions were as follows: 1 cycle of $5 \mathrm{~min}$ at $95^{\circ} \mathrm{C}$, followed by 39 cycles of $15 \mathrm{~s}$ at $95^{\circ} \mathrm{C}$ and $20 \mathrm{~s}$ at $52^{\circ} \mathrm{C}$. Melting curve analysis was $5 \mathrm{~s}$ incremental increases of $1{ }^{\circ} \mathrm{C}$ from 55 to $95{ }^{\circ} \mathrm{C}$.

Control reactions with primer and template free reaction mixtures were included. Two biological and three technical replicates were performed for each sample. The results were processed using the CFX Manager program.

\section{Results}

The response to DNA damage has been well characterized in Saccharomyces cerevisiae. It includes three groups of proteins involved in different types of DNA repair, termed the $R A D 3, R A D 52$ and $R A D 6$ epistasis groups. UV response is mediated by the $R A D 3$ group. The $R A D 52$ epistasis group genes have been implicated in the response to DNA double strand breaks. Although RAD3 and RAD52 repair pathways are relatively well understood, much less is known about the RAD6 mediated pathway. Mutations in the REV3 gene, a member of the RAD6 mutagenic repair pathway, are known to increase sensitivity to the lethal action of UV-light and to suppress mutagenesis. Our data demonstrate that himls epistatically interacts with rev3 3 , since the level of UV-induced mutagenesis in double mutants was decreased to the level of mutagenesis in single rev3 3 mutant (Kelberg et al. 2005). 
Thus, we have suggested that $H I M 1$ gene participates in the PRR.

Earlier, we have reported that spontaneous mitotic gene conversion in the $A D E 2$ locus in most heteroallelic combinations is increased ( twofold) in himl $\Delta$ strains compared to the wild-type strain (Ivanov et al. 1989). These data suggest that HIMI gene may be involved in the control of the recombination events. In this regard, we can assume that the HIM1 gene is involved in recombination (error-free) branch of PRR. The error-free post-replication repair involves the protein Rad5, with the assumed helicase activity (Johnson et al. 1992), and the protein Mms2, which acquires the ubiquitin-transferase activity when in complex with Ubc13p. Rad5-Mms2-Ubc13 provides PCNA polyubiquitylation, thus stimulating the recombination-like process associated with the helicase activity of Rad5p. MMS2 gene, therefore, acts in the first stage of the error-free branch of PRR. To test the hypothesis, that HIM1 gene may be involved in the control of the error-free branch of PRR, we deleted MMS2 gene from himl $\Delta$ mutant and the wild-type strain. UV resistance of $m m s 2 \Delta$ him $1 \Delta$ double mutant did not differ from $m m s 2$ single mutant (data not shown). As seen in Fig. 1, UV-induced mutagenesis in $m m s 2 \Delta$ strain is markedly lower than in himls, but is close to the level of mutagenesis in the wildtype strain. The error-prone branch of DDT has a seemingly limited ability to bypass large amounts of DNA damage, as supported by the work of Cejka et al (2001). Which showed that spontaneous damage in rad5 5 and $m m s 2 \Delta$ mutants leads

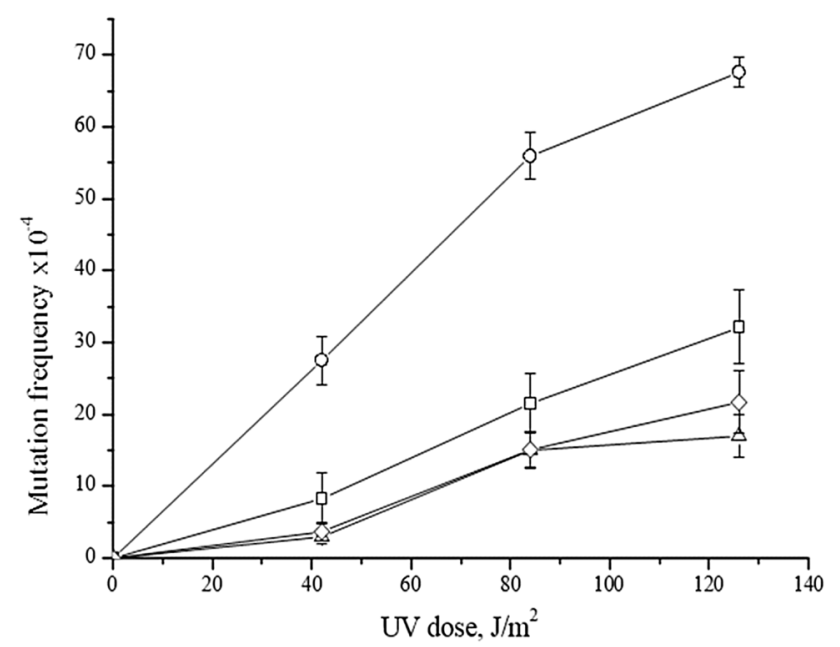

Fig. 1 UV-induced mutagenesis in various mutant strains. Isogenic derivatives of strain 11D-3031, were UV-irradiated. The mutation frequencies were determined, as a ratio of the number of white colonies to the number of all colonies grown in a cup with complete medium. Mutation frequency is plotted on a linear scale graph. The mean \pm SEM values obtained from four independent experiments are plotted. Mutant frequencies of the wild type strain (11D-3031) (open square); him $1 \Delta$ (1-EAA-3031) (open cirle); mms $2 \Delta$ (6-EAA-3031) (open triangle) and him $1 \Delta$ mms $2 \Delta$ (7-EAA-3031) (open diamond) to an approximately fivefold increase in mutagenesis. With a sharp increase in the number of DNA damage caused by low UV doses (less than $10 \mathrm{~J} / \mathrm{m}^{2}$ ), the level of induced mutagenesis increases by only 1.5 times (Broomfield and Xiao 2002). We work at high UV doses (at least $54 \mathrm{~J} / \mathrm{m}^{2}$ ), at which, apparently, there is a further decrease in the effectiveness of the mutagenic effect of UV. This is also confirmed by the data in the work of Lemontt in which one of the first alleles of the RAD5 gene was isolated according to the phenotype of a reduced level of UV-induced mutagenesis (Lemontt 1971). These data are consistent with our results that at high doses UV-induced mutagenesis in $m m s 2 \Delta$ mutant is close to the wild-type strain. The double mutant exhibits mutagenesis the same as a single $m m s 2 \Delta$ mutant. Therefore, $m m s 2 \Delta$ is epistatic to himls and himld induced mutagenesis is Mms2 dependent. It was shown that ssDNA gaps behind stalled replication forks are due to Mre11-dependent degradation of nascent DNA. The engagement of these gaps in Rad51dependent repair could prevent excessive nucleolytic degradation, sequestering the substrates once optimal Mre11dependent resection is achieved (Hashimoto et al. 2010). This gap resection facilitates the invasion of the newly synthesized sister chromatid by the nascent DNA strand, thus initiating TS. Consequently, the inactivation of the MRX complex can disrupt the TS and, as a result, suppress the

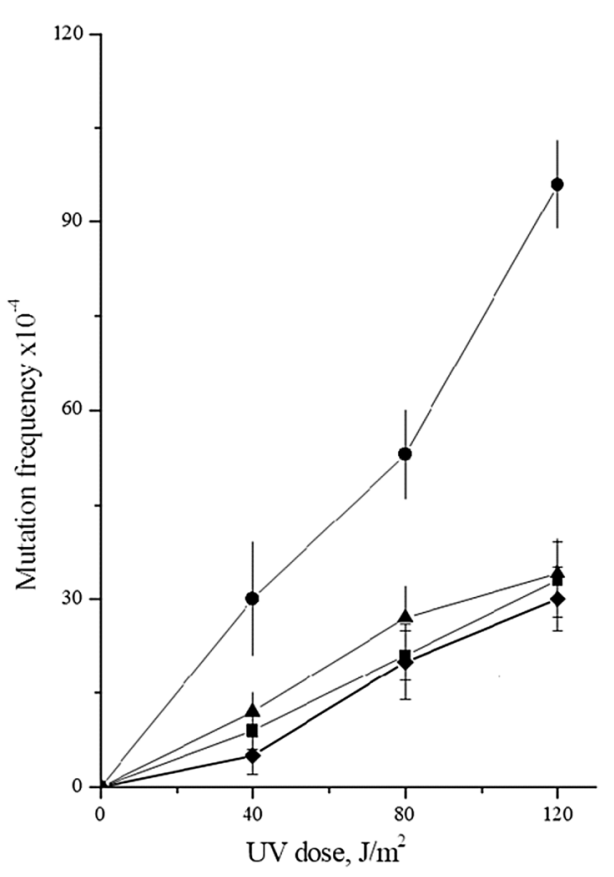

Fig. 2 UV-induced mutagenesis in various mutant strains. Isogenic derivatives of strain 11D-3031, were UV-irradiated. The mutation frequencies were determined as described for Fig. 1. Mutant frequencies of the wild type strain (11D-3031) (closed square); himls (1-EAA-3031) (closed circle); xrs $2 \Delta$ (2-ETA-3031) (closed triangle) and him $1 \Delta \operatorname{xrs} 2 \Delta$ (8-EAA-3031) (closed diamond) 
himl-dependent UV mutagenesis. To test this assumption, we examined potential epistatic relationships between mutations of XRS2 and HIM1 genes. XRS2 encodes a subunit of the MRX complex ( $\operatorname{Rad50,~Mre11,~Xrs2).~The~UV~resist-~}$ ance of $x r s 2 \Delta$ him $1 \Delta$ double mutant did not differ from $x r s 2$ single mutant (data not shown). xrs $2 \Delta$ himl $\Delta$ double mutant was as sensitive to UV-induced mutagenesis as $x r s 2 \Delta$ single mutant (Fig. 2). Taken together, these results strongly suggest that the HIM1 gene is involved in the error-free branch of damage bypass.

In contrast to the key genes that control the error-free branch of the PRR (RAD5, MMS2, MRE11), the mutations of which have practically no effect on the frequency of UVinduced mutagenesis or even decrease it, the deletion of the HIM1 gene leads to an increase in the yield of induced mutations (Kovaltzova 1973; Lemontt 1971). We were interested in understanding why there is a difference between him 1 and the rest of the error free proteins, considering that all of them somehow participate in the error free? In our previous work, we showed that a mutation in the HIMI gene leads to destabilization of the D-loop (Alekseeva et al.2018). Based on these results, it can be assumed that during PRR at the stage of D-loop processing.

It has been shown that Poln and Pold could extend the $3^{\prime}$ end in a D-loop (Li et al. 2009). Both polymerases were equally efficient in extending standard primed templates

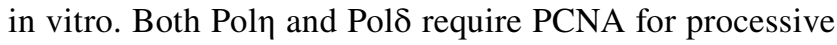
DNA synthesis. We hypothesized that the cause of himlmediated UV-induced mutagenesis is the replacement of Polס with highly erroneous Pol $\eta$ during the DNA synthesis in gaps after the destruction of the D-loop. To test this assumption, we deleted $R A D 30$ gene in the wild-type strain and him $1 \Delta$ mutant. The rad30 $\Delta$ single mutant showed UVinduced mutagenesis as the wild-type strain (Fig. 3). The UV-induced mutagenesis in the double himls rad30د mutant was the same as in the single rad30د mutant. Based on these results, it can be assumed that, in during PRR the Poln in himls mutant carries out reparative synthesis in unfilled gaps.

Mutations that arise during TLS at bipyrimidine sites, mainly formed as a result of UV-induced damage. In contrast, mutations at non-bipyrimidine sites frequently occur as a result of gap filling with Pol $\eta$. The CANI gene sequence contains $77 \%$ and $23 \%$ non-bipyrimidine sites (NBP) (Kozmin et al 2003). It can be assumed that the frequency of UV-induced mutations localized in NBP sites in the himls mutant will be higher than in the double himls rad $3 \Delta$ mutant. To get insight into the role of Poln in him 1dependent mutagenesis, mutation spectra were determined at the CANl locus in himls nd double himls rad30s strains for UVC. We isolated 200 canl mutants following UV irradiation at dose $84 \mathrm{~J} / \mathrm{m}^{2}$. The mutation frequencies
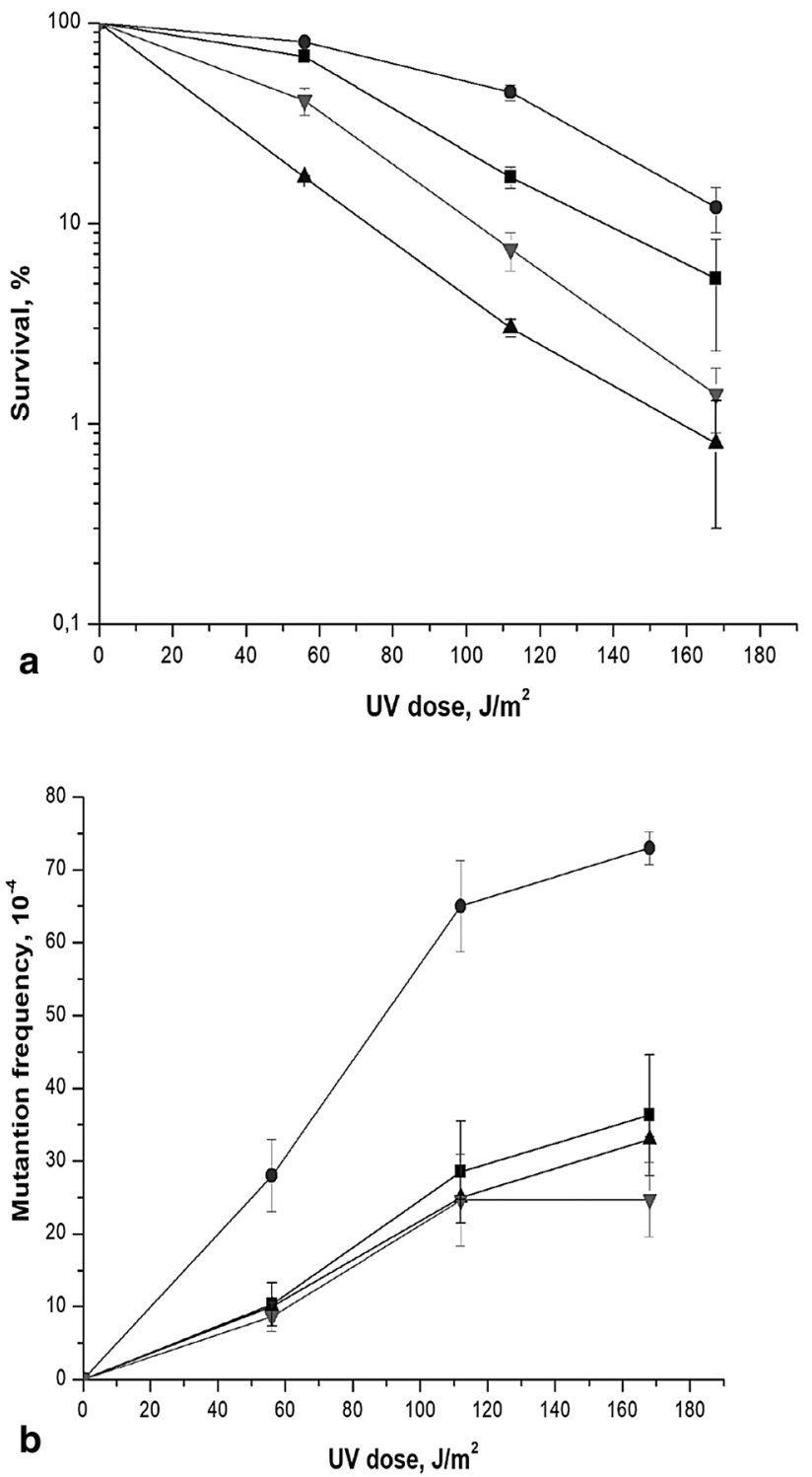

Fig. 3 UV-induced sensativity (a) and mutagenesis (b) in various mutant strains. Isogenic derivatives of strain 11D-3031, were UVirradiated. Aliquots were irradiated at the indicated dose, the viable titer was determined, and the percentage of survivals was calculated. The mutation frequencies were determined as described for Fig. 1.

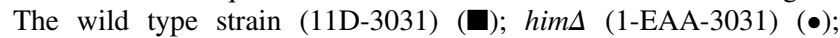

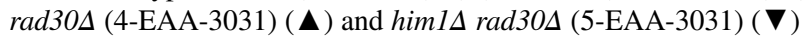

were $31 \times 10^{-5}$ and $10 \times 10^{-5}$ in $\operatorname{him} 1 \Delta$ and $\operatorname{him} 1 \Delta \operatorname{rad} 30 \Delta$ mutants, respectively.

The UV-induced spectra generated in himl and himls rad30 $\Delta$ background are characterized by a predominance of single base substitutions (Table 2). The spectrum of mutations obtained by us in him $1 \Delta$ rad30s mutant practically does not differ significantly from the mutation spectra in rad30s mutant obtained in the work (Kozmin et. al. 2003).

Genetics analysis of the molecular nature of ade2 mutants has revealed that himl-1 mutation increases specifically the 
Table 2 DNA sequence changes in UV-induced canl mutants in himls and himls rad30s strains

\begin{tabular}{|c|c|c|c|c|}
\hline \multirow[t]{2}{*}{ Mutation type } & \multicolumn{2}{|l|}{$\operatorname{him} 1 \Delta$} & \multicolumn{2}{|c|}{$\operatorname{him} 1 \Delta \mathrm{rad} 30 \Delta$} \\
\hline & $n(\%)$ & $f \times 10^{-5}$ & $n(\%)$ & $f \times 10^{-5}$ \\
\hline Base substitutions & $28(74)$ & 23 & $16(70)$ & 7 \\
\hline Frameshifts & $4(11)$ & 3.4 & $5(22)$ & 2.2 \\
\hline Tandem double & $4(10)$ & 3.1 & $1(4)$ & 0.4 \\
\hline Multiple & $2(5)$ & 1.5 & $1(4)$ & 0.4 \\
\hline
\end{tabular}

$f$ mutation frequency

Table 3 Types of base substitutions induced UV-light

\begin{tabular}{|c|c|c|c|c|}
\hline & \multicolumn{2}{|l|}{$\operatorname{him} 1 \Delta$} & \multicolumn{2}{|c|}{ him $1 \Delta \mathrm{rad} 30 \Delta$} \\
\hline & $n(\%)$ & $f \times 10^{-5}$ & $n(\%)$ & $f \times 10^{-5}$ \\
\hline \multicolumn{5}{|l|}{ Transitions } \\
\hline GCAT & $13(46)$ & 11.5 & $3(19)$ & 1.3 \\
\hline ATGC & $6(21)$ & 5.6 & $3(19)$ & 1.3 \\
\hline Transversions & $9(33)$ & 8 & $10(62)$ & 4 \\
\hline GCTA & 1 & 0.8 & 1 & 0.4 \\
\hline ATTA & 6 & 5.6 & 5 & 2 \\
\hline TAAT & 1 & 0.8 & 2 & 0.8 \\
\hline TAGC & - & - & 1 & 0.4 \\
\hline CGAT & 1 & 0.8 & 1 & 0.4 \\
\hline Total & 28 & - & 16 & - \\
\hline
\end{tabular}

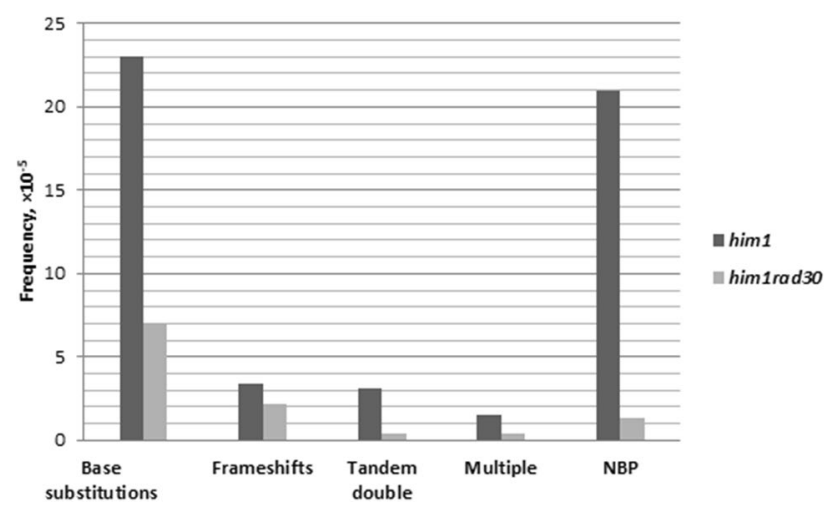

Fig. 4 The frequencies and types of base changes associated with defined sites induced by UV-light in $\operatorname{him} 1 \Delta$ (1-EAA-3031) (Poln works) and him $1 \Delta \operatorname{rad} 30 \Delta$ (5-EAA-3031) (Poln does not work)

yield of UV-induced transitions ( $\mathrm{AT} \rightarrow \mathrm{GC}$ and $\mathrm{GC} \rightarrow \mathrm{AT}$ ) in comparison with wild-type strains (Ivanov et al. 1987b). We compared the types of base changes induced by UVC

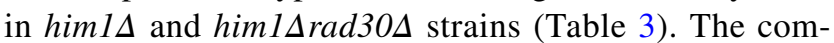
parison of types of base changes observed in himl $1 \Delta$ and him $1 \Delta$ rad $30 \Delta$ strains exhibits major differences. The frequency of transitions was robust decreased in himls rad30 $\Delta$ strain in comparison himls strain. The frequency of UV-induction mutations localized in the NBP sites (nonbipyrimidine sites) also varied significantly between himls $\left(21 \times 10^{-5}\right)$ and himls rad30s $\left(1.3 \times 10^{-5}\right)$ (Fig. 4). Taken together, data obtained show a significant role of Pol $\eta$ in him 1-dependent mutagenesis, especially at NBP sites.

What is the reason for the change of polymerases in himl mutant? It is known that during the PRR the overwhelming majority of D-loops dissociate without the formation of crossover exchanges (Freidberg et al. 2006). The length of the newly synthesized DNA in the D-loop depends on the rate of DNA synthesis and the probability of termination of this process. As a result of the stochasticity of the termination process, the length of the newly synthesized DNA will be different in each injury bypass event. However, the average length of the synthesized section will depend only on the speed of the synthetic process. The rate of DNA polymerase synthesis depends on the concentration of deoxynucleotides. Therefore, with a decrease in the concentration of dNTP, the average length of the synthesized section will decrease and with a significant decrease in concentration, it will not be able to bridge the gap in the damaged DNA. In Saccharomyces cerevisiae, dNTP pools increase by about three-fold upon entry into S-phase relative to $G_{1}$ levels (Szyika et al. 2008). dNTP levels show a three- to five-fold increase in response to DNA damage relative to a normal S-phase, through the check-point-dependent induction of $R N R$ genes, the allosteric regulation of RNR activity and the degradation of the Rnr1 inhibitor Sml1 (Zhao et al. 1998, 2001; Chabes et al. 2003). This increase in the amount of dNTP correlates with tolerance to DNA damage.

In order to test the effect of the concentration of dNTP on himl-dependent mutagenesis, we deleted the SML1 gene, which encodes a specific suppressor of the RNRI gene ( $R N R 3$ homologue), in wild-type and himl mutant strains. As a result, the expression of the RNR complex is significantly increased and, as a consequence, the concentration of dNTP also increases by a factor of 2-3 (Zhao, Muller, Rothstein 1998). As can be seen from Fig. 5, deletion of the SML1 gene lowers the level of UV-induced mutagenesis in comparison with the wild-type strain. Our experiments also demonstrated that smlla is able to suppress the higher UV-induced mutagenesis of himl $1 \Delta$ mutant (Fig. 5). Thus significant increase in the dNTP levels suppress himl-dependent mutagenesis.

To test the hypothesis that dNTP concentration regulates the choice of polymerase for loop extending, we examined UV-irradiated himl $\Delta$ cells for increased RNR3 expression. We irradiated with UV light the wild-type and him $1 \Delta$ mutant cells and, after $2 \mathrm{~h}$, measured the mRNA $R N R 3$ gene levels in the irradiated cells. As can be seen from Fig. 6, the mRNA level in wild-type cells increased 

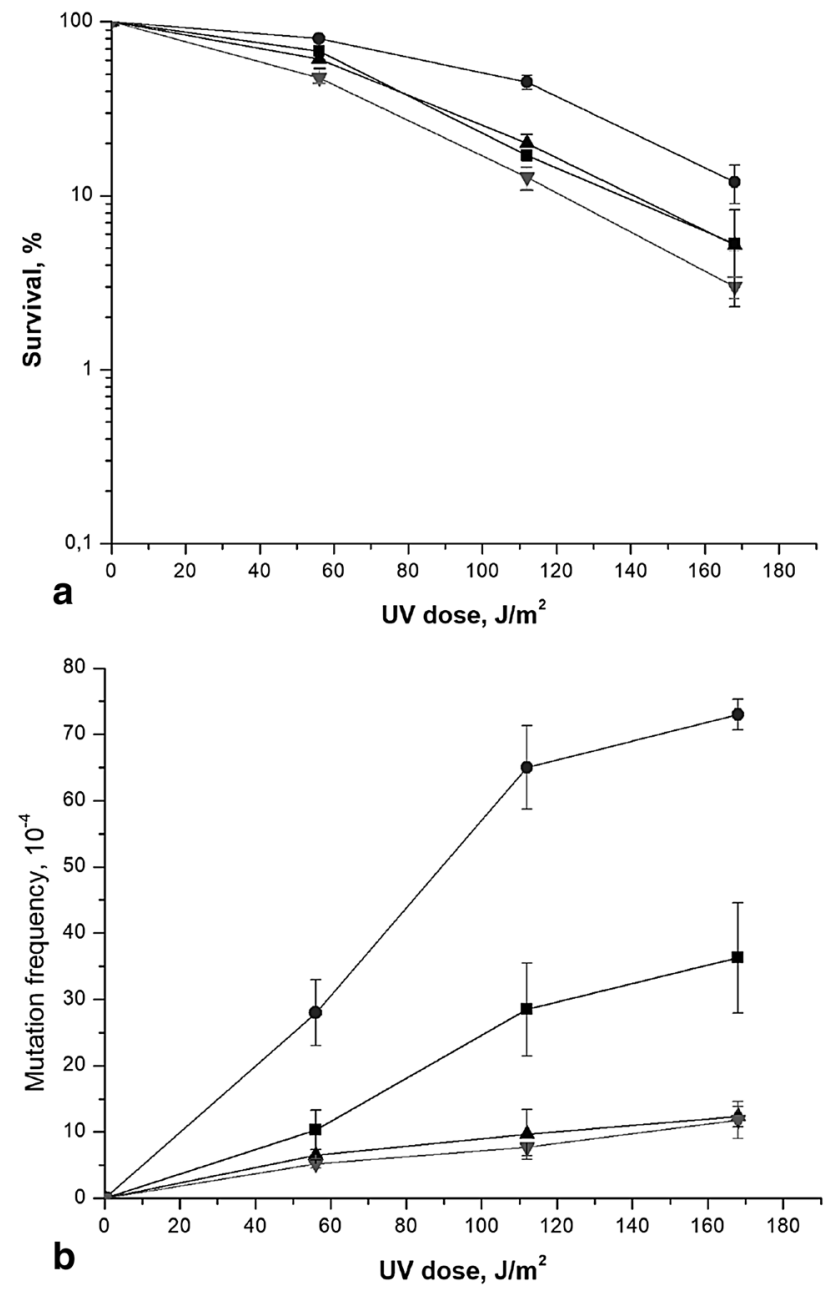

Fig. 5 UV-induced sensativity (a) and mutagenesis (b) in various mutant strains. Isogenic derivatives of strain 11D-3031, were UVirradiated. The survival and mutation frequencies were determined as described for Fig. 3. The wild type strain (11D-3031) (closed square); hims (1-EAA-3031) (closed circle); smlls (6-DVF-3031) (closed triangle) and himls smlls (7-DVF-3031) (closed inverted triangle)

sevenfold, while in mutant cells the increase did not reach twofold. This finding suggests that himl $1 \Delta$ mutation significantly reduces the efficiency of the induction expression of $R N R$ genes after UV irradiation. Reduced expression of $R N R$ genes will lead to decrease in dNTP concentration. Taken together, the results confirm the hypothesis that intermediate dNTP concentrations stimulate Pol $\eta$ recruitment to fill the gaps. Poln belongs to the highly erroneous polymerase family and this is the cause of the increased UV-induced mutagenesis in himls mutant.

\section{Discussion}

The DNA damage response is a powerful intracellular network that has the potential to repair damage and induce cell cycle arrest. To ensure that the DNA damage response works to the benefit of its host cell, it is essential that responses to DNA damage are properly regulated. Here, we have shown that Him1, a protein with unknown function and involved in the regulation of UV-induced mutagenesis and himls mutant Poln in himls mutant take part in reparative DNA synthesis.

Previous experiments have shown that himl-1 mutation displays weak mutator phenotype, increasing fivefold the level of spontaneous reversions of the ade2-42. Spontaneous mitotic gene conversion in the ADE2 locus in most heteroallelic combinations is increased ( twofold) in himls strains compared to the wild-type strain (Ivanov et al. 1989). Epistatic analysis showed a synergistic interaction of himls with pms $1 \Delta$, apn $1 \Delta$, and rad $2 \Delta$ mutations, and rev3s epistasis with $\operatorname{him} 1 \Delta$. Based on the data obtained, we proposed that HIMI gene participates in the control of processing of DNA damage that appears after UV irradiation (Kelberg et al. 2005). Here, we have shown that proteins Mms2, Xrs2, involved in the error-free branch of the PRR, have a crucial function in himl-dependent UV mutagenesis.

At what stage of the PRR process is HIMI taking part? We have previously shown that inactivation of two antirecombination helicases Srs2 and Mph1 suppresses him 1specific mutagenesis (Alekseeva et al. 2018). Both of these helicases destabilize the D-loops and decrease the average length of the synthesized DNA region (Rong and Klein 1993; Dupaigne et al. 2008; Colavito et al. 2009; Panico et al. 2010; Prakash et al. 2009). Consequently, their inactivation will lead to an increase in the length of the newly synthesized DNA in gaps, and this event is the reason for the suppression of himl-specific mutagenesis. On the other hand, deletion of the HSM2 gene (HMO1), the product of which stabilizes the D-loops, results in a phenotype similar to himls mutation (Ivanov et al. 1989; Alekseev et al. 2002; Kim and Livingston 2006, 2009; Gonzlez-Huici et al. 2014).

From this, it follows that the change of polymerases occurs after the destruction of the D-loop and the gap is filled with an erroneous polymerase.

Earlier, we have shown that himl-1 and pms $1 \Delta$ mutations have a synergistic effect on UV-induced mutagenesis (Kelberg et al. 2005). The level of induced mutagenesis in him $1 \Delta$ pms $1 \Delta$ double mutant was significantly higher than in both single mutants. On the other hand, single pms $1 \Delta$ mutant and the wild-type strain have the same level of UVinduced mutations. This is not surprising, since an incorrectly incorporated nucleotide opposite to UV-induced damage (pyrimidine dimers) is not a substrate for mismatch 
Fig. 6 Relative normalized expression of the RNR3 gene in wild-type (11D-3031) and himls (1-EAA-3031) mutant cells before and after UV irradiation. a UV dose at $252 \mathrm{~J} /$ $\mathrm{m}^{2} ; \mathbf{b}$ UV dose at $140 \mathrm{~J} / \mathrm{m}^{2}$. ${ }^{*} p>0.05$, Student's $t$ test
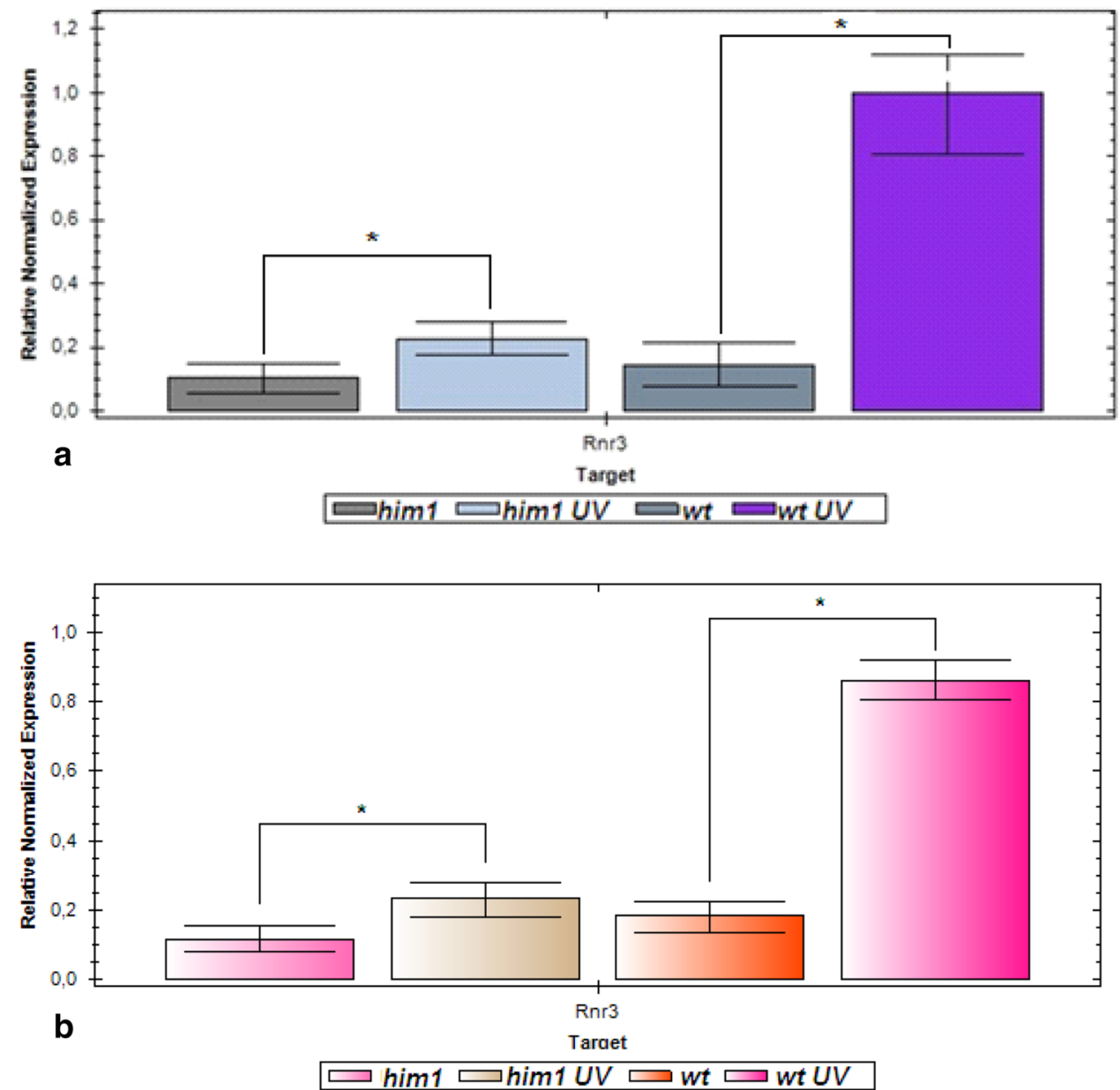

repair. Furthermore, disruption of PMS1 gene in double hsm $2 \Delta$ him $1 \Delta$ mutant increases the UV-induced mutation frequency in the triple mutant up to the frequency of single hsm $2 \Delta$ mutant (Kelberg et al. 2005). These data indicate that after the destruction of the D-loop, the gaps are filled with an erroneous Pol $\eta$. Since the mismatch repair PMS1 gene is not directly related to damage-induced mutagenesis, we suggested that mismatch repair substrates arose in the cells of himls mutant as a result of the attraction of this polymerase to the synthesis of DNA into the gaps. Consistent with this conclusion, we found that Pol $\eta$ inactivation completely blocks him 1-dependent UV mutagenesis. On the other hand, our data showed that Poln-dependent mutagenesis in NBP sites occurs significantly more frequently in $\operatorname{him} 1 \Delta$ mutant than in the double himls rad30s mutant. This result indicates that during the DDT, the Poln effectively works on an intact template into the gaps.

On the basis of the data obtained, it is possible to construct a hypothetical mechanism for an error-free repair branch (Fig. 7). After the competition for access to the primer end of DNA in the stopped replication fork wins the MRX complex. The degradation of the newly synthesized DNA strand begins and a gap is created before the damage
(Fig. 7a). The released 3'- end is coated with RPA protein, which attracts recombination machinery (Rad51, Rad52, $\operatorname{Rad55}, \operatorname{Rad} 57)$ and a nucleoprotein filament is formed (Fig. 7b). The specific helicase Srs2 destroys a significant portion of these filaments, displacing the Rad51 protein. The rest of the filaments are introduced into sister chromatid, forming a D-loop structure (Fig. 7c). Rad51 protein-free filaments are possibly captured by the Rad5 protein and are also incorporated into sister chromatid. As a result, D-loop structures are generated. At the same time, another specific helicase Mph1 and other proteins, begin, the effective work of which ultimately leads to the destruction of the hybrid DNA (Fig. 7d). The length of the newly synthesized DNA region will depend on the ratio of the speeds of the synthesis of the strand and hybrid DNA destruction. Normally, in wild-type cells, the rate of synthesis due to the extremely high concentration of deoxynucleotides apparently will be approximately equal to the rate of unwinding of the strands. As a result, the length of the newly synthesized fragment of the strand will exceed the length of both gaps around the damage and an error-free damage bypass will take place (Fig. 7e). 
Fig. 7 The process of DNA damage error-free bypass. Stall replicative complex is recognized by the Mre11-Rad50-Xrs2 (MRX) complex. MRX initiates resection of newly synthesised DNA strand. The exposed ssDNA is bound by RPA. After RPA is replaced by Rad51, the Rad51 filament is formed, which is introduced into the sister chromatid, leading to the formation of D-loop. Details in the text

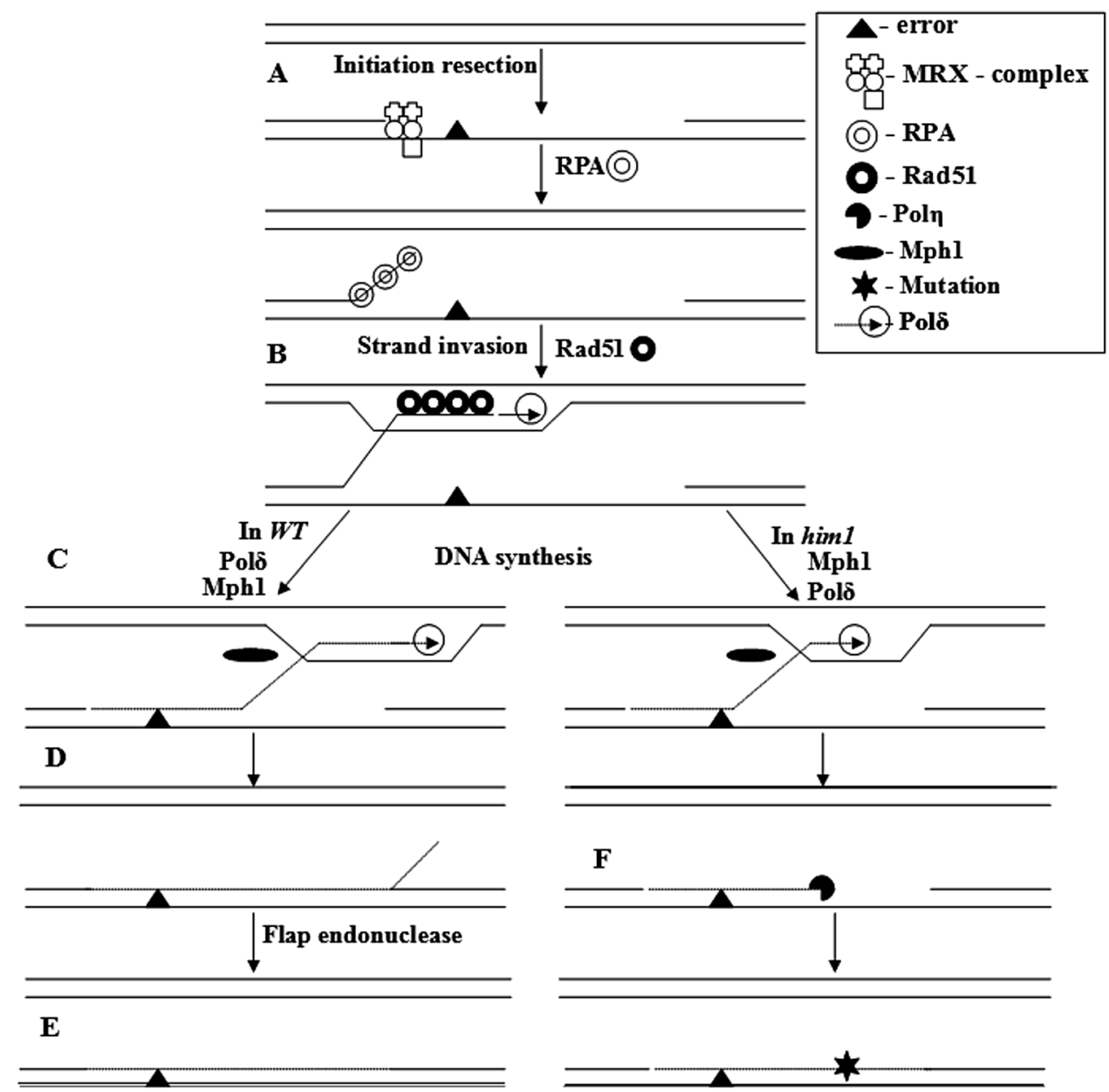

We proposed and showed that mutations in HIM1 gene affect the efficiency of the induction of the RNR complex and, as a result, decrease the concentration of deoxynucleotides after UV in the nucleoplasm. This leads to a drop in the rate of repair DNA synthesis and shifts the equilibrium towards the premature collapse of the hybrid DNA. After annealing the released strand on the mother duplex, the 3'-terminus occupies Poln (Fig. 7f). After the first error,

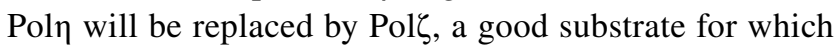
are unpaired bases at the end of the primer. The latter, apparently, will complete the development of the remaining gap.

In conclusion, this study identifies the HIM1 gene as a novel member of error-free pathway of DDT (Figs. 1, 2). Interestingly, the mechanism through himls mutant acts by recruiting polymerase Poln to carry out reparative DNA synthesis during DDT. It will be interesting in the future to determine how does the Him1 protein affect the regulation of RNR gene expression.

Acknowledgements The work has been performed as part of the Genome Research Center development program "Kurchatov Genome Center - PNPI" (agreement №. 075-15-2019-1663).
Open Access This article is licensed under a Creative Commons Attribution 4.0 International License, which permits use, sharing, adaptation, distribution and reproduction in any medium or format, as long as you give appropriate credit to the original author(s) and the source, provide a link to the Creative Commons licence, and indicate if changes were made. The images or other third party material in this article are included in the article's Creative Commons licence, unless indicated otherwise in a credit line to the material. If material is not included in the article's Creative Commons licence and your intended use is not permitted by statutory regulation or exceeds the permitted use, you will need to obtain permission directly from the copyright holder. To view a copy of this licence, visit http://creativecommons.org/licenses/by/4.0/.

\section{References}

Alekseev SY, Kovaltsova SV, Fedorova IV, Gracheva LM, Evstukhina TA, Peshekhonov VT, Korolev VG (2002) HSM2 (HMO1) gene participates in mutagenesis control in yeast Saccharomyces cerevisiae. DNA Repair 1:287-297. https://doi.org/10.1016/s1568 -7864(02)00005-8

Alekseeva EA, Evstukhina TA, Peshekhonov VT, Korolev VG (2018) Interaction of the HIM1 gene product with helicases Srs2 (Radh) and Mph1 yeast Saccharomyces cerevisiae. Cytology 60(7):555557. https://doi.org/10.31116/tsitol.2018.07.13 
Ball LG, Zhang K, Cobb JA, Boone C, Xiao W (2009) The yeast Shu complex couples error-free post-replication repair to homologous recombination. Mol Microbiol 73:89-102. https://doi.org/10.111 1/j.1365-2958.2009.06748.x

Branzei D, Vanoli F, Foiani M (2008) SUMOylation regulates Rad18mediated template switch. Nature 456:915-920. https://doi. org/10.1038/nature07587

Broomfield S, Xiao W (2002) Suppression of genetic defects within the $R A D 6$ pathway by $s r s 2$ is specific for error-free post-replication repair but not for damage-induced mutagenesis. Nucleic Acids Res 30:732-739. https://doi.org/10.1093/nar/30.3.732

Brusky J, Zhu Y, Xiao W (2000) UBC13, a DNA-damage-inducible gene, is a member of the error-free postreplication repair pathway in Saccharomyces cerevisiae. Curr Genet 37:168-174. https ://doi.org/10.1007/s002940050515

Cejka P, Vondrejs V, Storchova Z (2001) Dissection of the functions of the Saccharomyces cerevisiae RAD6 postreplicative repair group in mutagenesis and UV sensitivity. Genetics 159:953-963

Chabes A, Georgieva B, Domkin V, Zhao X, Rothstein R, Thelander L (2003) Survival of DNA damage in yeast directly depends on increased dNTP levels allowed by relaxed feedback inhibition of ribonucleotide reductase. Cell 112:391-401. https://doi. org/10.1016/s0092-8674(03)00075-8

Chernenkov AY, Gracheva LM, Evstyukhina TA, Kovaltsova SV, Peshekhonov VT, Fedorova IV, Korolev VG (2012) Interaction of gene HSM3 with genes of the epistatic RAD6 group in yeast Saccharomyces cerevisiae. Russ J Genet 48:139-145. https:// doi.org/10.1134/S102279541201005X

Chernenkov AY, Fedorov DV, Gracheva LM, Evstuhina TA, Kovaltsova SV, Peshekhonov VT, Fedorova IV, Korolev VG (2012) Interactions of the HSM3 Gene with genes initiating homologous recombination repair in yeast Saccharomyces cerevisiae. Russ J Genet 48(3):284-290. https://doi.org/10.1134/S1022 795412020056

Colavito S, Macris-Kiss M, Seong C, Gleeson O, Greene EC, Klein HL, Krejci L, Sung P (2009) Functional significance of the Rad51-Srs2 complex in Rad51 presynaptic filament disruption. Nucleic Acids Res 37:6754-6764. https://doi.org/10.1093/nar/gkp748

Dupaigne P, Le Breton C, Fabre F, Gangloff S, Le Cam E, Veaute X (2008) The Srs2 helicase activity is stimulated by Rad52 filaments on dsDNA: implication for crossover incidence during mitotic recombination. Mol Cell 29:243-254. https://doi.org/10.1016/j. molcel.2007.11.033

Fedorova IV, Kovaltzov SV, Gracheva LM, Evstyuhina TA, Korolev VG (2004) Requirement of HSM3 gene for spontaneous mutagenesis in Saccharomyces cerevisiae. Mutat Res 554:65-75

Friedberg EC (2005) Suffering in silence: the tolerance of DNA damage. Nat Rev Mol Cell Biol 6:943-953. https://doi.org/10.1038/nrm1781

Freidberg EC, Walker GC, Siede W, Wood RD et al (2006) DNA repair and mutagenesis, 2nd edn. ASM Press, Washington, p 1161

Ganesan AK (1974) Persistence of pyrimidine dimmers during post-replication repair in ultraviolet light-irradiated Escherichia coli K12. J Mol Biol 87:103-119. https://doi.org/10.1016/0022-2836(74)90563 $-4$

Giannattasio M, Zwicky K, Follonier C, Foiani M, Lopes M, Branzei D (2014) Visualization of recombination-mediated damage bypass by temple switching. Nat Struct Mol Biol 21:884-892. https://doi. org/10.1038/nsmb.2888

Gonzlez-Huici V, Szakal B, Urulangodi M, Psakhye I, Castellucci F, Menolfi D, Rajakumara E, Fumasoni M, Bermedjo R, Jentsch S, Branzei D (2014) DNA bending facilitates the error-free DNA damage tolerance pathway and upholds genome integrity. EMBO J 28:327-340. https://doi.org/10.1002/embj.201387425

Hashimoto Y, Chaudhuri AR, Lopes M, Costanzo V (2010) Rad51 protects nascent DNA from Mre11 dependent degradation and promotes continuous DNA synthesis. Nat Struct Mol Biol 17:1305-1311. https://doi.org/10.1038/nsmb.1927

Ivanov EL, Koval'tsova SV, Korolev VG (1987) Mutants of the yeast Saccharomyces cerevisiae characterized by enhanced induced mutagenesis. I. Isolation and preliminary characterization of mutants. Genetika (Moscow) 23:784-792 (PMID: 3305160)

Ivanov EL, Kovaltzova SV, Korolev VG (1987) Yeast (Saccharomyces cerevisiae) mutants with enhanced induced mutagenesis. III. Influence of him mutations on effectiveness and specificity of UVinduced mutagenesis. Genetika (Moscow) 23:1555-1563

Ivanov EL, Kovaltzova SV, Korolev VG (1989) Saccharomyces cerevisiae mutants with enhanced induced mutation and altered mitotic gene conversion. Mutat Res 213:105-115. https://doi.org/10.1016/00275107(89)90141-3

Johnson RE, Henderson ST, Petes TD et al (1992) Saccharomyces cerevisiae RAD5-encoded DNA repair protein contains DNA helicase and zinc-binding sequence motifs and affects on stability of simple repetitive sequences in the genome. Mol Cell Biol 12:3807-3818. https://doi.org/10.1128/mcb.12.9.3807

Karras GI, Fumasoni M, Sienski G, Valoni F, Branzei D, Jentsch S (2013) Noncanonical role of the 9-1-1 clamp in the error-free DNA damage tolerance pathway. Mol Cell 49:536-546. https://doi.org/10.1016/j. molcel.2012.11.016

Kelberg EP, Kovaltsova SV, Yu AS, Fedorova IV, Gracheva LM, Evstukhina TA, Korolev VG (2005) HIM1, a new yeast Saccharomyces cerevisiae gene playing a role in control of spontaneous and induction mutagenesis. Mutat Res 578:64-78. https://doi.org/10.1016/j. mrfmmm.2005.03.003

Kim H, Livingston DM (2006) A high mobility group protein binds to long CAG repeat tracts and establishes their chromatin organization in Saccharomyces cerevisiae. J Biol Chem 281:15735-15740. https ://doi.org/10.1074/jbc.M512816200

Kim H, Livingston DM (2009) Suppression of a DNA polymerase delta mutation by the absence of the high mobility group protein Hmol in Saccharomyces cerevisiae. Curr Genet 55:127-138. https://doi. org/10.1007/s00294-009-0229-y

Kovaltzova SV (1973) Reparation and mutagenesis III. Effect of mutations to radiosensitivity on UV induced forward mutations and reversions in ADE2 locus in Saccharomyces cerevisiae. Genetica (Moscow) 9(3):110-115

Koval'tsova S.V., Korolev V.G, (1996) The Saccharomyces cerevisiae yeast strain for testing environmental mutagens based on the interaction between $\mathrm{rad} 2$ and himl mutations . Russ J Genet 32:366-372

Kozmin SG, Pavlov YI, Kunkel TA, Sage E (2003) Roles of Saccharomyces cerevisiae DNA polymerases Poln and Pol $\zeta$ in response to irradiation by simulated sunlight. Nucl Acids Res 31:4541-4552. https://doi.org/10.1093/nar/gkg489

Lemontt JF (1971) Mutants of yeast defective in mutation induced by ultraviolet light. Genetics 68(1):21-33

Li X, Stith CM, Burgers PM, Heyer W-D (2009) PCNA is required for initiation of recombination-associated DNA synthesis by DNA polymerase. Mol Cell 36:704-713. https://doi.org/10.1016/j.molce 1.2009.09.036

Panico ER, Ede C, Schildmann M, Schurer KA (2010) Genetic evidence for a role of Saccharomyces cerevisiae Mph1 in recombinational DNA repair under replicative stress. Yeast 27:11-27. https://doi. org/10.1002/yea. 1727

Prakash L (1981) Characterization of postreplication repair in Saccharmyces cerevisiae and effects of rad6, rad18, rev3 and rad52 mutations. Mol Gen Genet 184:471-478. https://doi.org/10.1007/bf00352525

Prakash R, Satory D, Dray E, Papusha A, Scheller J, Kramer W, Krejci L, Klein H, Haber JH, Sung P, Ira G (2009) Yeast Mph1 helicase dissociates Rad-51made D-loop: implications for crossingover control in mitotic recombination. Genes Dev 23:67-79. https://doi. org/10.1101/gad.1737809 
Roman H (1956) A system selective for mutations affecting the synthesis of adenine in yeast. Comp Rend Trav Lab Carlsberg Ser Physiol 26:299-314

Rong L, Klein HL (1993) Purification and characterization of the SRS2 DNA helicase of the yeast Saccharomyces cerevisiae. J Biol Chem 268:1252-1259 (PMID: 8419328)

Sale JE (2012) Competition, collaboration and coordination-determining how cells bypass DNA damage. J Cell Sci 125:1633-1643. https ://doi.org/10.1242/jcs.094748

Szyika SJ, Aparicio JG, Viggiani CJ, Knott S, Xu W, Tavare S, Aparicio OM (2008) Rad53 regulates replication fork restart after DNA damage in Saccharomyces cerevisiae. Genes Dev 22:1906-1920. https ://doi.org/10.1101/gad.1660408

Ulrich HD (2009) Regulating post-translational modifications of the eukaryotic replication clamp PCNA. DNA Repair 8:461-469. https ://doi.org/10.1016/j.dnarep.2009.01.006

Vanoli F, Fumasoni M, Szakal B, Maloisel L, Branzei D (2010) Replication and recombination factors contributing to recombinationdependent bypass of temple switch. PLoS Genet. 6:e1001205. https ://doi.org/10.1371/journal.pgen.1001205
Zakharov IA, Kozhin SA, Kozhina TA, Fedorova IV (1984) Sbornik metodik po genetike drozhzhei-sakharomitsetov Methods of yeast Saccharomycescerevisiae genetics. Nauka, Leningrad

Zhao X, Muller EGD, Rothstein R (1998) A suppressor of two essential checkpoint genes identifies a novel protein that negatively affects dNTP pools. Mol Cell 2:329-340. https://doi.org/10.1016/s1097 $-2765(00) 80277-4$

Zhao X, Chabes A, Domkin V, Thelander L, Rothstein R (2001) The ribonucleotide reductase inhibitor Sml1 is a new target of the Mec1/ Rad53 kinase cascade during growth and in response to DNA damage. EMBO J 20:3544-3553. https://doi.org/10.1093/emboj $/ 20.13 .3544$

Publisher's Note Springer Nature remains neutral with regard to jurisdictional claims in published maps and institutional affiliations. 